\title{
Public Area Surveillance and Police Work: the impact of CCTV on police behaviour and autonomy.*
}

\author{
Benjamin J. Goold ${ }^{1}$
}

\begin{abstract}
Drawing on a recent study of the impact of closed circuit television (CCTV) cameras on policing practices in a large English police force, this paper considers whether the presence of surveillance cameras affects the working attitudes and behaviour of individual police officers. In particular, this paper asks whether CCTV makes the police more accountable or more cautious in the exercise of their discretion in public spaces. Although noting that in certain circumstances CCTV may inadvertently help to reduce incidences of police misconduct, this paper concludes by arguing that more needs to be done to prevent the police from interfering with the operation of CCTV and gaining unauthorised access to potentially incriminating video evidence.
\end{abstract}

\section{Introduction}

Over the past decade, the United Kingdom has become the most watched citizenry in Europe. ${ }^{2}$ Since the early 1990s, over one million closed circuit television (CCTV) cameras have been installed in towns and cities across Britain, with an estimated 500 or more being added to this figure every week (Gadher, 1999). ${ }^{3}$ As a consequence, CCTV cameras can now be found in most urban high streets, town squares and shopping centres, as well as in many offices, car parks and stores.

One of the most important questions raised by the spread of closed circuit television in Britain is whether public area surveillance has brought about any significant changes in

\footnotetext{
* Thanks are due to Lisa Gourd and Matthew Silverstein for their help with earlier drafts of this paper, and to my three anonymous reviewers for their insightful criticisms and suggestions.

${ }^{1}$ Associate Professor of Anglo-American Law, Faculty of Law, Niigata University, Japan, and adjunct professor, Department of Law and Police Science, John Jay College of Criminal Justice, New York.

${ }^{2}$ According to Barbara Morgan, the former Director of the National CCTV Users Group, there are 'more cameras here in proportion to the population than anywhere else, including the United States. The UK is the largest user of CCTV in the world.' Quoted in Gadher, 1999.

${ }^{3}$ See also Appleyard, 2001. According to one estimate, some 300,000 security cameras are sold each year, the result being a video surveillance industry worth something in the vicinity of $£ 300$ million.
} 
the way in which police officers behave and exercise their powers. ${ }^{4}$ As both supporters and opponents of CCTV have argued, closed circuit cameras have the potential to transform not only how the policing of urban centres is organized, but also the working practices and attitudes of individual police officers. Does the presence of cameras affect the way in which police officers work in public? For example, does knowing that they are being watched by CCTV influence officers' decisions to use force when making arrests? Do cameras make the police more accountable and less autonomous? In an effort to answer these questions, this paper examines evidence from a recent study of the impact of CCTV cameras on police practices and attitudes in a large English police force, and considers whether the introduction of this technology has led police officers to reevaluate their behaviour or their relationship with the public that they police and protect.

\section{The Research Study}

This paper draws on research carried out between June 1997 and March 2000 in six towns with CCTV in the south of England. Of the towns included in the study, three - A1, A2, and A3 - operated public area CCTV schemes that were housed on police premises and managed by the police. The remaining schemes - in B1, B2, and B3 - were entirely owned and operated by local authorities, with the police having only minimal input into decisions regarding the aims and operation of the system. In the course of the main research study - carried out between March 1998 and June 1999 - approximately 330 hours were spent observing CCTV operators and police officers in these six towns, and a total of 95 formal interviews were conducted. Of these interviews, 50 were with police officers ranging from the rank of police constable (PC) to Chief Inspector and Assistant Chief Constable, the remaining 45 being with civilian camera operators, scheme managers, and local officials. ${ }^{5}$

The primary aim of this research was to examine the impact of CCTV cameras on a large police force (the "Southern Region Force"), focusing in particular on policing strategies, resource management, and the working practices of individual officers. Police officers at each of the six schemes were asked their opinions about if and how the introduction of cameras had affected them and their colleagues when on patrol and when responding to incidents within the town centre. In addition, officers were asked to describe their own feelings about being watched by the cameras, and whether they favoured the continued use of CCTV surveillance in their local area.

\footnotetext{
${ }^{4}$ For a more general discussion of the issues raised by the police use of surveillance technology, see work by: Garland, 2001; Manning, 1992; Marx, 1988; and Rule, 1973. The theoretical and public policy implications of the current study are examined in detail in my book, CCTV and Policing in Britain, to be published by Oxford University Press later this year.

${ }^{5}$ In order to give each individual the opportunity to explain themselves fully, a semi-structured interview format was followed. As the interviews were tape-recorded and transcribed verbatim, the individual respondents' method of describing and explaining their behaviour was preserved. By the end of the research period, the interview data consisted of approximately 40 hours of taped interviews, which once transcribed ran to over 900 typed pages.
} 


\section{Policing the Police}

Traditionally, one of the key features of street-level policing has been the large degree of autonomy enjoyed by individual officers. Although in principle the powers employed by the police - such as stop-and-search and the power of arrest - are regulated by law and subject to various forms of review, in practice decisions made at street level are rarely, if ever, directly supervised or exposed to external criticism (Wilson, 1969: 17). Unlike most other forms of organisation, in the police service personal discretion increases as one moves down the hierarchy, with the effect that officers on the street exercise considerable power over the public:

[B]ecause police tasks at the lower level are ill-defined, episodic, nonroutine, accomplished in the regions of low visibility, and are dispatched in ways that most often bypass the formal chain of command in the organisation, control over the work resides largely in the hands of those who perform the work. In this sense, police agencies resemble symbolic or mock bureaucracies where only the appearance of control, not the reality, is of central concern.

(Van Maanen, 1983: 277) ${ }^{6}$

As Holdaway (1983) and others have noted, the police have historically been keen to maintain this autonomy, either by ensuring that decision-making continues to enjoy lowvisibility, or by resisting the efforts of the government and others to impose restrictions on the exercise of officer discretion (Holdaway, 1979). ${ }^{7}$ As researchers discovered in the years following the introduction of Police and Criminal Evidence Act 1984 (PACE), the police are extremely adept at circumventing rules which attempt to limit their powers or constrain their discretion. ${ }^{8}$ With the introduction of public area CCTV, however, many police officers now find themselves faced with the prospect of being watched and possibly recorded as they go about their daily routine on the job. ${ }^{9}$

When asked whether the introduction of surveillance cameras had affected their work, the majority of police officers interviewed initially responded by stating that the presence of CCTV had not had any impact on the way in which they carried out their duties or

\footnotetext{
${ }^{6}$ See also: Goldstein, 1960; and Manning, 1977.

${ }^{7}$ See also Holdaway, 1983 and Choongh, 1997.

8 As McConville, Sanders and Leng have noted: 'As a general rule, conformity with the detailed substantive and procedural rules is not an important consideration for police officers in respect of most of their powers. Thus, powers of stop-and-search do not inform police decision making but rather rationalise behaviour undertaken for other reasons.' (McConville, Sanders and Leng, 1991: 183). See also: Sanders and Young, 2000: 90; Dixon, Coleman and Bottomley, 1990; and Dixon, Bottomley, Coleman, Gill and Wall, 1989.

${ }^{9}$ The idea that police are subject to surveillance from their own devices is, of course, nothing new. As Ericson and Haggerty point out, 'the very communication formats and technologies police officers use to conduct surveillance of others are also used for surveillance of their own work.' (Ericson and Haggerty, 1997: 35). Indeed, Manning goes further to suggest that far from being autonomous agents, the police are in fact dominated by the very machines that serve them: 'They are servants of the public in name only, for although the public pays them, they work for the machines that lurk behind them, glow in front of them, click and buzz in their ears and fill the air with dull electronic sounds.' (Manning, 1988: 155).
} 
exercised their powers. Comments such as 'I don't really notice the cameras' and 'You don't really think about being recorded until afterwards' were common, as were statements such as the following:

Being watched by the cameras doesn't bother me in the slightest. And it shouldn't - it shouldn't bother anyone because your job shouldn't change because the cameras are there. You should be doing it by the book wherever you go, whether the cameras are watching you or not. So to that end, no, it doesn't affect me at all ... Sometimes you might go away thinking, 'Was that excessive?' And then you look at the cameras, and nine times out of ten, no, it's not. I did everything fine then.

PC 2, Town A1

At the end of the day, we've just got to make sure what we do is by the letter of the law and according to our own guidelines and procedures. And as long as police officers aren't doing anything wrong, it's the same for them as for the public: they have nothing to worry about.

PC 3, Town A1

The cameras certainly don't affect the way that I deal with things. I'm not thinking as I'm going to an incident, 'Oh, I've got to be careful because CCTV is there.' I mean, you deal with an incident as you find it.

\section{PC 1, Town B2}

When pressed on the issue of how CCTV had affected their behaviour on the streets, however, over two-thirds of the officers interviewed conceded that the introduction of cameras had forced them to be 'more careful' when out on patrol. ${ }^{10}$ Some, for example, had heard stories of officers being prosecuted for unlawful arrest or assault on the basis of CCTV evidence, stories that had left them anxious about being watched and the possibility of their own activities being scrutinised. Others, particularly younger officers, found being under constant surveillance made them nervous and uncomfortable. Irrespective of the reason for their concern, many of these officers had come to the conclusion that the introduction of CCTV made it essential for them to 'go by the book', or at least to create the appearance of doing so. As one officer at town A1 confessed:

It affects our thinking of things a lot because obviously the cameras are there to identify possible crime about to happen, or even people who are actually committing crimes at the time. But having said that, it also records police actions. Therefore when you arrive at an incident, you've got to be aware of the fact that the cameras are watching you. We are being recorded, the same as anybody else. Therefore what we do has to be right, it has to look right. Therefore it makes it quite a priority for most officers entering the town centre - they're thinking, 'I'm on camera.'

\footnotetext{
${ }^{10}$ For obvious reasons, this was something that was difficult to "observe" in the course of the fieldwork, and as such the conclusions set out in this section rely primarily on statements made by operators and officers in interview.
} 


\section{PC 3, Town A1}

In a similar vein, another officer at town A1 - after some reflection - also admitted that the introduction of cameras had affected the thinking of officers at the station, particularly those who, in his opinion, needed to improve their approach to policing the town centre:

I think CCTV is good for everybody. It can't not be. I mean, the only negative thing I can think of is if perhaps officers were not doing what they should be doing when they're arresting people and speaking to people, but then those people shouldn't be doing the job, in my opinion. So, if the cameras are forcing them to perhaps think about the way they're policing and think about doing it properly, then I think it's a good thing.

PC 4, Town A1

In the course of informal conversations with police officers at towns A1 and A2, it also became clear that many officers working at these stations had been 'warned' by their shift sergeants and local inspectors to remember that they were being watched by the cameras, and to be particularly aware of CCTV whenever they attended an incident in the town centre. In a small number of cases, officers had received more specific advice, namely about making sure that when they effected an arrest they did so in view of the cameras, in part for the purposes of evidence but more importantly to protect themselves against unfounded complaints of unlawful or excessively forceful arrest. According to one shift sergeant at town A2, it was essential for officers to make use of the cameras and to incorporate them in their day-to-day thinking when working the town centre 'for their own sake as well as for the sake of the community'. As a consequence, during shift briefings he made a point of reminding officers of the presence of CCTV and suggested ways in which they could turn CCTV to their advantage, such as making sure that the camera operators were actually watching and recording an incident before the police arrived, so that if trouble developed the tape would help to put the actions of the police in their 'proper' context.

The opinion that care needed to be taken with CCTV to ensure that police actions were not 'misinterpreted' was one that was frequently expressed by officers of all ranks during the course of the research. Although the majority of officers interviewed initially claimed to be unconcerned or unaffected by the presence of CCTV cameras, over time it became apparent that many harboured private concerns about the possibility of their actions suddenly being exposed to external scrutiny. According to a number of PCs at town A2, for example, officers around the station had become increasingly worried about the prospect of CCTV evidence being used 'against police officers', particularly by the Police Complaints Authority. In part, these apprehensions may have been sparked by concern over a complaint made about a local officer that eventually led to his suspension for unlawful arrest. Central to the accusation was CCTV footage taken by local cameras, which showed the officer using his baton to effect an arrest. According to the officer concerned - who had returned to the station but had been taken off town centre patrol duty - part of the 'problem' in his case was that the tape only told part of the story: 
An incident started up in one of the local night-clubs and spilled out violently onto the street. At some point, I had to use my baton on someone. I felt at the time that I had used it just as we had practised, but that incident went to court and the magistrates viewed the videotape from the CCTV cameras. I believe that because they didn't understand the techniques they saw, they misunderstood the amount of force that had been used ...

PC 3, Town A2

Although circumspect about his suspension and its effect on his career, the officer claimed that the incident had forced him to reconsider his previous opinion of CCTV and its use by the police. In particular, he argued that his own experience had suddenly made him acutely aware of how misleading camera footage could be, and of the need for police officers, lawyers, and the courts to become more wary of relying solely on CCTV evidence:

The essential problem with the CCTV is that it cannot capture the perception of the people or officers actually experiencing the situation. If you see two people fighting and it gets caught on the video, it doesn't tell you the background to it, it doesn't necessarily tell you what happened immediately before, and sometimes it doesn't tell what happened during or immediately after. I think that is one of the main downfalls of CCTV. Many people see it as a panacea, when really and truly it has got some quite severe difficulties.

PC 3, Town A2

Going further, this officer also stressed that part of the problem arose from the fact that unless magistrates and prosecutors understood police techniques, it was likely that the number of successful but unfounded complaints based on CCTV evidence of arrests would eventually begin to rise:

People who are involved in the criminal justice system who get to see CCTV evidence have to be given some advice on the police techniques that they may see on CCTV. Because there are no two ways about it. Some police techniques, some of the restraints we use, do look violent. But that's only because they haven't seen the technique being trained or seen the officers being trained in it.

PC 3, Town A2

During the weeks spent at town A2, it became clear that the experiences of the suspended officer had become well known around the local police station, and had led other PCs and more senior officers to reconsider their own opinions about CCTV. Although in conversation the majority of PCs played down the incident and described it as either 'unfortunate' or a 'one-off', according to one officer the affair had affected the way he and other officers approached potentially difficult situations during their shifts: 
I think they are a lot more cautious about being hands on. And certainly a lot more cautious with the use of force. And that tends, in my personal view, to go against the training we are told to use, and has the potential to make officers more vulnerable. My personal feeling is that there will come an occasion, it might not happen now and it might not happen tomorrow, but sometime an officer will get a severe beating or even worse as a result of possibly being over-cautious.

\section{PC 4, Town A2}

This suggestion that the introduction of cameras had made some police officers less willing to use force on the streets was echoed by several CCTV operators during the course of the study. At towns A1, A2 and B3, for example, camera operators complained on numerous occasions about what they saw as the reluctance of officers to step in and end fights that had been detected by the cameras. One operator at town B3 became particularly incensed when describing an incident where, after being called to a fight outside a nightclub, two patrol officers had remained in their car observing the fight for almost ten minutes before finally deciding to attempt to arrest the main protagonists. It is difficult to determine, however, whether this reluctance on the part of the officers stemmed from a fear of being 'caught on camera' and possible exposure to complaints about the use of force, or whether it simply represented a healthy concern for their own safety.

In any event, during the course of the study it became increasingly clear that officers at all of the towns were worried about the possibility of camera footage being used in support of complaints against them or their colleagues. Notwithstanding the suspension of the officer at town A2, however, there was no clear evidence to suggest that the introduction of CCTV into the Southern Region had actually led to an increase in the number of complaints against the police. ${ }^{11}$ An examination of the tape logs at each of the six schemes, for example, revealed only two clear instances of tapes being removed in connection with complaints against the police. In addition, statements made by a handful of senior officers suggested that when CCTV footage was called upon in response to a complaint against a police officer, it usually worked in the officer's favour, often resulting in the complaint being dropped altogether. According to one Inspector at town A2, for example, the presence of CCTV had led to a reduction in the number of filed, formal complaints being made against his officers:

I deal with complaints as an inspector, and quite often you have people come in and complain. Then you'll go and look at the video, and quite often they actually back up the officer's side of things because lots of these things are night-time type confrontations, and people's memories of them are clouded by alcohol ...

Police Inspector, Town A1

\footnotetext{
${ }^{11}$ Although the overall number of complaints had risen marginally during the period immediately following the introduction of cameras, nearly all of this rise could be attributed to a change in Force policy regarding the distinction drawn between formal and informal complaints.
} 
Given that it is rare for complaints to be made or upheld on the basis of CCTV evidence, why were officers in the Southern Region concerned about the possibility of video footage being used against them? In part, their concern may have stemmed from an awareness of the fact that - at a national level at least - CCTV footage is increasingly being used by the Police Complaints Authority in England to investigate complaints against police officers. In an article published by The Sunday Times, for example, it was reported that during 1999 alone CCTV footage was used in nearly 300 successful complaints against police officers, and that more recent figures suggest that this number is on the rise (The Sunday Times, 2000: 5). As Richard Offer, as spokesperson for the PCA, observed when being interviewed for the article, CCTV can be used to protect the public not only from crime and criminals, but also from the police:

It has been used to tackle crime, but one side-effect has been that it makes it much easier to deal with police complaints ... It is giving citizens protection against errant officers, and officers protection on malicious complaints. It's certainly a valuable tool.

(The Sunday Times, 2000: 5) ${ }^{12}$

The concern expressed by officers during the course of the study may, the refore, have had less to do with how CCTV was actually being used to investigate complaints in the Region, and more to do with a fear about how CCTV might be used against them in the future. Whatever the reason, however, officers reported that this concern had translated into more circumspect behaviour on the part of many PCs, particularly when it came to using force or making arrests within view of the cameras. This being the case, it is important to consider whether the presence of CCTV led officers to alter their behaviour in other less positive ways.

\section{Staying out of Sight}

Having established that many of the police officers interviewed for the study were conscious of being monitored by CCTV, the question arises as to whether the introduction of cameras produced any form of 'protective response' from these same officers. Certainly, previous studies of the police have suggested that officers will attempt to circumvent external supervision or surveillance wherever possible, either to disguise specific incidents or to maintain an environment of low visibility in which the exercise of police discretion can take place. As a case in point, Ericson and Haggerty (1997) found that Canadian police officers go to considerable lengths to avoid being the subjects of video surveillance:

Like other police technologies, video cameras are potentially able to trace police officer activity. However, we found that there were a number of ways in which this capacity was circumvented. For example, officers might position the camera in a way which would produce a recording fashioned to induce the viewer to empathize with the officers rather than

\footnotetext{
${ }^{12}$ See also The Independent, 2000.
} 
the suspect. As one officer declared, 'I'm not a great lover of Rodney King or anything, but it will be nice to show our side of things fr a change.'

(Ericson and Haggerty, 1997: 139).

Turning to the more specific case of public area CCTV, Norris and Armstrong (1999) reported that at one of the CCTV schemes included in their study operators were occasionally given a signal by police officers - typically by raising their arm and waving their hand - to move the cameras away from a potentially sensitive or embarrassing incident. In one case, for example, four town centre officers were 'caught' by the cameras standing in a group talking when they should have been on patrol, with the result being a signal to the CCTV operator to move the cameras away quickly before they were spotted by their superiors:

When this [the signal to the operator to move away] was also spotted by the Controller the message both silently from those surveilled and verbally from behind him was move the camera - which the operator did. The Controller went on to explain that the Divisional Commander had his monitor on and if he saw four patrol officers standing in a group he would 'go mad'.

(Norris and Armstrong, 1999: 89-190).

In addition, Norris and Armstrong (1999) also found evidence to suggest that the police occasionally either ignored or suppressed CCTV footage that may have given support to a formal complaint or forced the police to take disciplinary action against a serving officer:

One Thursday night a large-scale public order situation was a product of a local officer leaving a night-club and picking a fight with three black youths. The latter sitting in a car outside a snooker club were approached by him and were not impressed by his suggestion that drug dealers like them should 'fuck off to where they came from'; in the ensuing fight the CCTV system located the PC, shirt off brawling as more black youths spilled out of the snooker club. The end product was the deployment of 20 uniformed officers to the scene and the spiriting away in the rear of the police car the offending officer. Two black youths were arrested. According to the CCTV operator the tape was never released to either the police or any other agency and the officer was ne ver disciplined for his actions.

(Norris and Armstrong, 1999: 190).

Although in the current study there was no evidence to suggest that officers had actually directed operators to deflect attention from them, there was reason to believe that police officers at some of the schemes had attempted to remove tapes that they feared might contain footage of police misconduct. At the police-led schemes, operators claimed that on a number of occasions officers had come up to the CCTV control room following incidents in which they had been required to use force and had asked to 'check the tape'. 
One camera operator at town A2, for example, complained of having to ask officers to leave the control room after they had attempted to remove a tape from the previous day a tape that showed one of them restraining a young woman who had allegedly resisted arrest. According to the operator, many of the officers at the station did not appear to regard themselves as being bound by the scheme's Code of Practice rules on tape handling and access to evidence, and he went so far as to joke that the padlock on the tape storage cupboard was not there to protect the tapes from the possibility of theft from intruders, but rather from theft by police officers. Although when interviewed the operator downplayed the incident and claimed that the officers were easily dissuaded from trying to take the tapes, it was clear that some tension had arisen as a result of the incident, and that the operators had subsequently begun to take issues of system and tape security far more seriously.

As might be expected, episodes of this kind appeared more likely to take place at policeled schemes, in part because the police had greater access to the CCTV control room and in part because police-led operators and police officers tended to enjoy closer working relations. ${ }^{13}$ It was also clear from interviews with both the police and CCTV operators that officers working in conjunction with police-led schemes were more inclined to view the system as existing primarily for their benefit, and often displayed signs of regarding themselves as the 'rightful' owners of all evidence produced by the cameras. This general attitude may explain why some officers at police-led schemes felt comfortable asking operators for access to tapes and, on rare occasions, bold enough to attempt to remove tapes without authorisation. In contrast, none of the operators interviewed at local authority-led schemes claimed that local police officers had attempted either to direct cameras away from them or to gain unauthorised access to tapes. In light of the fact that relations between operators and officers at these schemes were rarely as friendly as at the police-led schemes, this lack of interference on the part of the police is perhaps to be expected. Operators working at local authority schemes were rarely visited by local police officers, and therefore any efforts by those officers to interfere with the system would have been not only unwelcome but obvious as well.

Given some of the fears that have been expressed by civil libertarians regarding the possibility of CCTV being misused by the police, these findings suggest that there is indeed some reason to be concerned about the independence and integrity of police-led CCTV systems. It could be argued, for example, that as police-led schemes are more susceptible to police interference than local authority-led schemes, the police should be prevented from running public area CCTV systems altogether. However, none of the systems considered in the course of this study were even subject to comprehensive or effective regulation. On the other hand, none of the codes of practice or procedural guidelines at any of the schemes - police- or local authority-led - were sufficiently welldrafted or consistently enforced so as to ensure that the systems were safe from outside

\footnotetext{
${ }^{13}$ This conclusion is based on comments made in interviews by operators at both police and local authorityled schemes. On the whole, operators at police-led schemes were far more likely to identify tape security as a serious problem than their local authority counterparts, and almost all operators interviewed at police ledschemes were able to point to at least one occasion in which the police had ignored Code of Practice guidelines regarding access to video tapes.
} 
interference. As a consequence, a degree of caution needs to be exercised before drawing the conclusion that police-led CCTV schemes are more vulnerable than local authorityled schemes. What is clear, however, is that effective regulation is especially important in the case of police-led schemes, if only because the possibility of police interference with such systems is inevitably higher.

\section{Conclusion}

There is always a need to be cautious when generalizing from a single empirical study. The above findings, however, raise some important questions about the potential use of public area surveillance technologies like CCTV. If it is true, for example, that the presence of video cameras in town and city centres tends to make police officers more circumspect in the execution of their duties in public, is it possible to turn CCTV into a full-fledged and effective system of police supervision? Does the emergence of surveillance technologies like CCTV require us to rethink issues related to police accountability and the visibility of discretion? Certainly if existing CCTV systems are to be used to help "police the police", serious issues about the organization and ownership of public area CCTV need to be addressed. In particular, much more needs to be done to ensure that CCTV operators are not subject to undue pressure from the police, nor required to defend the security and integrity of CCTV schemes from unauthorised interference from officers.

In addition, the potential unwillingness of the police to use force when CCTV surveillance is in effect is an issue that must be considered. While it may be desirable to use CCTV as a means of monitoring police conduct in public, this must be weighed against the danger of placing officers in the position of constantly second-guessing themselves, particularly when dealing with potentially violent incidents or uncooperative members of the public. To be an effective supervisory tool, it is essential that CCTV does not become something that is feared or deliberately avoided by the police.

Finally, these findings remind us of just how closely public area CCTV surveillance has come to resemble Jeremy Bentham's original idea of the Panopticon. Although in the wake of Foucault's Discipline and Punish there has been a tendency for criminologists and sociologists to see surveillance technologies like CCTV in terms of social control, it is important to remember that for Bentham one of the great virtues of his panoptic prison was that it exposed prison guards as well as prisoners to outside scrutiny. As Janet Semple observes,

The final application of the inspection principle was of the whole of the prison by the whole of the outside world. The central tower would enable judges and magistrates to inspect the prison quickly and safely... The design of the building would also enable any member of the public safely to enter the prison and to view every prisoner in it: "I take it for granted, as a matter of course, that... the doors of these establishments will be, as, without very special reasons to the contrary, the doors of all public 
establishments should be, thrown wide open to the body of the curious at large - the great open committee of the tribunal of the world."

(Semple, 1993: 142).

In helping to bring about the "panopticisation" of streets and city centres, surveillance cameras have the potential to do more than simply change the way we see and use public spaces. Whether intended or not, the spread of CCTV may also have sparked a transformation in the very nature of police work, and the move towards a society in which ordinary police officers, like Bentham's prison guards, are no longer able to avoid the public gaze. ${ }^{14}$

\section{References}

Appleyard, B. (2001) Nowhere to hide. The Sunday Times Magazine, 15 April.

Choongh, S. (1997) Policing as social discipline. Oxford: Clarendon Press.

Dixon, D., K. Bottomley, C. Coleman, M. Gill and D. Wall (1989) Reality and rules in the construction and regulation of police suspicion. International Journal of the Sociology of Law 17 (2): 185-206.

Dixon D., C. Coleman and K. Bottomley (1990) Consent and the legal regulation of policing, Journal Of Law And Society 17(3): 345-362.

Ericson, R. and K. Haggerty (1997) Policing the Risk Society. Oxford: Clarendon Press.

Foucault, M. (1977) Discipline and Punish: The Birth of the Prison. London: Allen Lane.

Gadher, D. (1999) Smile, you're on 300 candid cameras... The Sunday Times, 14 February.

Garland, D. (2001) The Culture of Control: Crime and Social Order in Late Modernity. Oxford: Oxford University Press.

Goldstein, J. (1960) Police Discretion not to invoke the criminal process: low visibility decisions in the administration of justice. Yale Law Journal, 63: 543-594

Holdaway, S. (1979) The British Police. London: Arnold.

Holdaway, S (1983) Inside the British Police. Oxford: Blackwell.

The Independent (1996) Thousands of new cameras filming streets, 18 January. Manning, P. (1977) Police Work. Cambridge Massachusetts: MIT Press.

\footnotetext{
${ }^{14}$ For a different perspective on this issue (based on a study of the use of CCTV in police custody suites), see Newburn and Hayman, 2002.
} 
Manning, P. (1988) Symbolic Communication: Signifying Calls and the Police Response. Cambridge Massachusetts: MIT Press.

Manning, P (1992) Information technologies and the police, in M. Tonry and N. Morris (eds.) Modern Policing. Chicago: University of Chicago Press, 349-398.

Marx, G. (1988) Undercover: Police Surveillance in America. Berkeley: University of California Press.

McConville, M., A. Sanders and R. Leng (1991) The Case for the Prosecution. London: Routledge.

Newburn, T. and Hayman, S. (2002) Policing, Surveillance and Social Control: CCTV and Police Monitoring of Suspects. Culhompton, Devon: Willan.

Norris, C. and G. Armstrong (1999) The Maximum Surveillance Society: The Rise of CCTV. Oxford: Berg.

Rule, J. (1973) Private Lives, Public Surveillance. London: Allen-Lane.

Sanders, A. and R. Young (2000) Criminal Justice (2 ${ }^{\text {nd }}$ ed.). London: Butterworths.

Semple, J. (1993) Bentham's Prison: A Study of the Panopticon Penitentiary. Oxford: Clarendon Press.

The Sunday Times (2000) Street cameras turn tables on police behaving badly, 13 Augus t.

Van Maanen, J. (1983) The Boss: First-line supervision in an American Police Agency, in M. Punch (1983) Control in the Police Organisation. Cambridge, MA: MIT Press, 275-317.

Wilson, J. (1969) Varieties of Police Behaviour. Cambridge Massachusetts: Harvard University Press. 